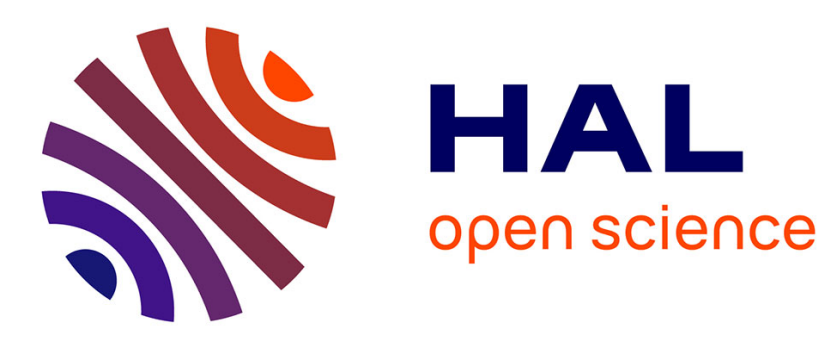

\title{
Thermal stabilization of polyamide 11 by phenolic antioxidants
}

Octavie Okamba-Diogo, François Fernagut, Jean Guilment, Frederique Pery, Bruno Fayolle, Emmanuel Richaud

\section{- To cite this version:}

Octavie Okamba-Diogo, François Fernagut, Jean Guilment, Frederique Pery, Bruno Fayolle, et al.. Thermal stabilization of polyamide 11 by phenolic antioxidants. Polymer Degradation and Stability, 2020, 179, pp.1-8. 10.1016/j.polymdegradstab.2020.109206 . hal-02890436

\section{HAL Id: hal-02890436 https://hal.science/hal-02890436}

Submitted on 6 Jul 2020

HAL is a multi-disciplinary open access archive for the deposit and dissemination of scientific research documents, whether they are published or not. The documents may come from teaching and research institutions in France or abroad, or from public or private research centers.
L'archive ouverte pluridisciplinaire HAL, est destinée au dépôt et à la diffusion de documents scientifiques de niveau recherche, publiés ou non, émanant des établissements d'enseignement et de recherche français ou étrangers, des laboratoires publics ou privés. 


\title{
Thermal stabilization of polyamide 11 by phenolic antioxidants
}

\author{
Octavie Okamba-Diogo ${ }^{\mathrm{a}, \mathrm{b}}$, François Fernagut ${ }^{\mathrm{b}}$, Jean Guilment ${ }^{\mathrm{b}}$, Frederique Pery ${ }^{\mathrm{b}}$, \\ Bruno Fayolle a, Emmanuel Richaud ${ }^{\text {a, * }}$ \\ a Arts et Metiers Institute of Technology, CNRS, CNAM, PIMM, HESAM Université, 75013, Paris, France \\ b ARKEMA, CERDATO, LEM, Route du Rilsan, 27470, Serquigny, France
}

Keywords:

Polyamide

Hindered phenols

Thermal oxidation

Induction period

\begin{abstract}
A B S T R A C T
This paper addresses the effect of hindered phenols (mainly Irganox 1098 with a few comparisons with other phenolic antioxidants) on the stabilization of polyamide 11 aged at several temperatures (90 $-165^{\circ} \mathrm{C}$ ). The effect of several phenol concentrations (up to about $0.4 \%$ ) on kinetic curves for imide buildup, yellowing, and molar mass changes (in association with embrittlement) was investigated. Phenols significantly contribute to yellowing, even at low imide concentrations. When they are used at high concentrations, a post-polycondensation reaction becomes predominant at earlier exposure times, thus increasing molar mass and significantly delaying embrittlement.
\end{abstract}

\section{Introduction}

Polyamides (PAs) are a family of technical thermoplastic polymers that cover a wide range of temperatures of use. Their semicrystalline morphology along with the presence of polar groups renders them quite resistant to various chemicals, particularly hydrocarbons [1-3]. They are widespread in several industrial applications (e.g., flexible offshore pipes, textiles, sporting gear). In the case of PA11, the end-of-life criteria (from a mechanical point of view) were previously determined and associated with critical values of molar mass and crystalline ratios [4]. The critical molar mass can be easily predicted from kinetic models, at least in the case of unstabilized PA, while changes in the crystallinity ratio can be determined from the chemicrystallization yield [5,6].

We will now describe the effect of antioxidants at both the molecular and macromolecular levels and then establish the kinetic models adapted to the case of stabilized PAs. Previously published papers illustrate well the effect of copper salts [7-9] or phenolic stabilizers on thin PA6 films [7,10,11], for example, when the oxidation is not controlled by oxygen diffusion. In the case of thick samples, antioxidants were shown to change the shape and thickness of oxidation profiles [9] and possibly the subsequent embrittlement of the polymer. The physical parameters describing the

\footnotetext{
* Corresponding author.

E-mail address: emmanuel.richaud@ensam.eu (E. Richaud).
}

action of Irganox 1098 were also estimated [12]. They are valuable inputs for predicting the lifetime of stabilized polymers using semiempirical [13-15] or physical models that take into account the reactivity of polymers and their stabilizers [16-18].

In this work, we will focus on the case of PA11, including phenolic stabilizers. We will observe the main phenomena associated with stabilizers through a multiscale analysis aimed at tracking the residual antioxidant (using thermal analysis $[19,20]$ ), the stable carbonyl products [21], the macromolecular changes (linked to chain scission, crosslinking, and post-polycondensation [4]), and the effect of oxidation on aesthetical properties, namely yellowing (UV spectroscopy [21,22]). For this purpose, we investigated the case of PA11 stabilized with Irganox 1098 (a common antioxidant in polyamides) at various initial concentrations and then made comparisons (at a given concentration) with other phenolic antioxidants.

\section{Experimental}

\subsection{Materials}

Stabilized PA were obtained by mixing pure PA11 (BESNO grade described in Ref. [3]) and Irganox ${ }^{\circledR} 1098$ (CAS 23128-74-7, $\mathrm{M}=637 \mathrm{~g} \mathrm{~mol}^{-1}$ ) considered to be the reference stabilizer often used for PA stabilization, as the presence of the amide function improves its compatibility with the polymer matrix. We therefore 
prepared four materials at various Irganox ${ }^{\circledR} 1098$ concentrations $(0.02,0.04,0.12$, and $0.4 \%)$ to investigate the influence of phenol concentration on oxidation. Some comparisons were made with Irganox 1010 (CAS 6683-19-8, $\mathrm{M}=1176 \mathrm{~g} \mathrm{~mol}^{-1}, 0.14 \%$ ) and Irganox 245 (CAS 36443-68-2, $\mathrm{M}=562 \mathrm{~g} \mathrm{~mol}^{-1}, 0.12 \%$ ). The structures of stabilizers are given in Fig. 1. Their weight percentages were quantified by high-performance liquid chromatography after extrusion according to the procedure described in Ref. [20]. It should be emphasized that a small part of the antioxidants could remain either physically trapped between crystalline lamellae or chemically linked by a transamidation reaction; as a result, the weight amounts provided may be a slight underestimation.

PA11 (BESNO grade) and stabilizers were mixed as a dry blend prepared to follow the composition. The powder blend was processed into pellets using a twin-screw extruder (HAAKE 2) prior to the preparation of the film into a single-screw extruder at $240{ }^{\circ} \mathrm{C}$ (Randcastle) so as to obtain $50-100 \mu \mathrm{m}$ thin films. The diffusionlimited oxidation effect was not observed in the case of unstabilized samples [4]. It is assumed that the same applied to stabilized samples, since the oxidized layers would be thicker for stabilized than for unstabilized samples [9].

\subsection{Ageing}

PA11 films were placed in an air-ventilated oven XUO 32 (France Etuves) at a temperature range between 90 and $165^{\circ} \mathrm{C}$. The samples were dried overnight under vacuum at $50^{\circ} \mathrm{C}$ before aging.

\subsection{Characterization}

\subsubsection{Fourier-transform infrared spectroscopy}

Infrared spectra were collected in transmission mode using a PerkinElmer Frontier spectrophotometer in the range 4000$400 \mathrm{~cm}^{-1}$ at $4 \mathrm{~cm}^{-1}$ optical resolution and 32 scan repetitions. The overall carbonyl concentration was measured based on the direct measurement of absorbance at $1734 \mathrm{~cm}^{-1}$ with $1800 \mathrm{~cm}^{-1}$ as the reference absorbance using $2851 \mathrm{~mol}^{-1} \mathrm{~cm}^{-1}$ as the molar absorptivity [21].

\subsubsection{Gel permeation chromatography}

The molar mass of PA11 films was determined by Gel Permeation Chromatography (GPC). Samples were dissolved in 1,1,1,3,3,3hexafluoroisopropan-2-ol (>99\% purity - VWR) at a concentration of $1 \mathrm{mg} \mathrm{ml}^{-1}$. After gentle manual agitation, the solution was kept overnight at room temperature, filtered on Acrodisc CR PTFE
$0.2 \mathrm{~mm}$ (Pall Light Sciences), and injected in the chromatograph (Water alliance 2695). The separation was performed using a precolumn and two columns packed with 7-mm particles and $1000 \AA$ and $100 \AA$ A pore size, both supplied by Polymer Standards Services (PSS), Mainz, Germany. The dimension of the columns was $8 \mathrm{~mm}$ ID $\times 300 \mathrm{~mm}$ length. The columns were thermostated at $40{ }^{\circ} \mathrm{C}$ while the mobile phase was a mixture of HFiP $-0.05 \mathrm{~mol} \mathrm{l}^{-1}$ potassium trifluoroacetate with a $1 \mathrm{ml} \mathrm{min}^{-1}$ flow rate and $100 \mu \mathrm{l}$ injection volume. The detection module was performed using a WATERS 410 differential refractive index detector and data treated using PSS WinGPC unity v.5 SEC software. The calibration was built using poly(methylmethacrylate) standards (Polymer Laboratories Varian) with the molar mass ranging between 420 and $1,900,000 \mathrm{~g} \mathrm{~mol}^{-1}$, while the calibration curve was adjusted with an order 5 polynomial. The repeatability of this technique is usually considered to be very good (less than $5 \%$ deviation) [23].

\subsubsection{Thermal analysis}

PA11 film samples ( $5 \mathrm{mg})$ were characterized by standard oxidation onset temperature (OOT) measurements using a DSC Q20 apparatus (TA Analysis) driven by Q Series Explorer as described in Ref. [17,18]. The procedure involved a simple ramp temperature change of $10^{\circ} \mathrm{C} \mathrm{min}^{-1}$ under oxygen atmosphere from 50 to $250{ }^{\circ} \mathrm{C}$ after $5 \mathrm{~min}$ isotherm at $50{ }^{\circ} \mathrm{C}$ under nitrogen. OOT corresponds to the intersection of the baseline after the melting peak, with the slope occurring at the inflection point of the rising oxidation exotherm.

\subsubsection{UV-visible spectrophotometry}

Transmission UV-visible spectra were recorded on freestanding films on a PerkinElmer Lambda $35 \mathrm{UV} /$ Vis spectrophotometer between 200 and $500 \mathrm{~nm}$.

\section{Results \& discussion}

\subsection{Build-up of stable products}

During ageing, PA underwent structural changes as depicted in Fig. 2, where a broad absorption progressively appeared due to the appearance of stable species (carboxylic acids, imide) as already discussed elsewhere [21]. It appears that the phenolic antioxidants have no effect on the shape of the signal, contrary to the comparison of additive-free oxidized PP [24] with PP + Hindered Amine Stabilizers [25], where the difference in Fourier-transform infrared spectra could originate from the regenerative nature of amine<smiles>CC(C)(C)c1cc(CCNC(=O)CCCCNC(=O)CCCCCNC(=O)CCc2cc(C(C)(C)C)c(O)c(C(C)(C)C)c2)cc(C(C)(C)C)c1O</smiles>
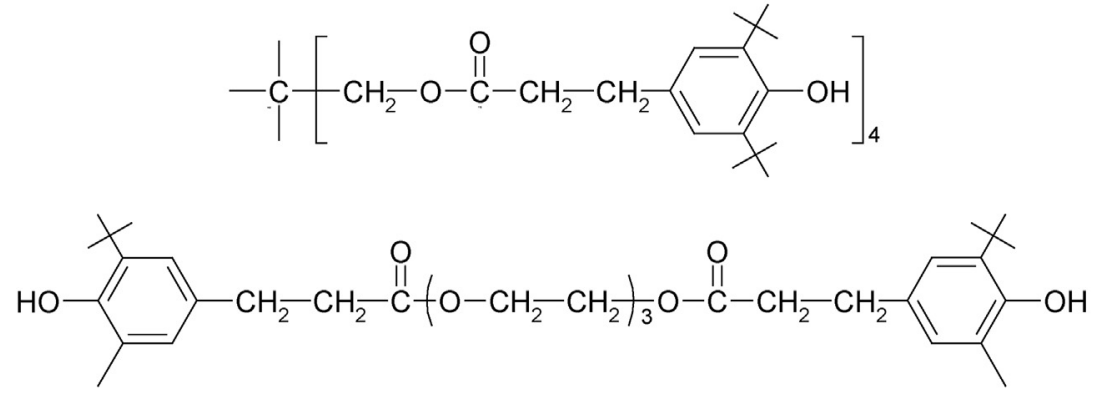

Fig. 1. Structure of Irganox 1098 (a), Irganox 1010 (b), and Irganox 245 (c). 


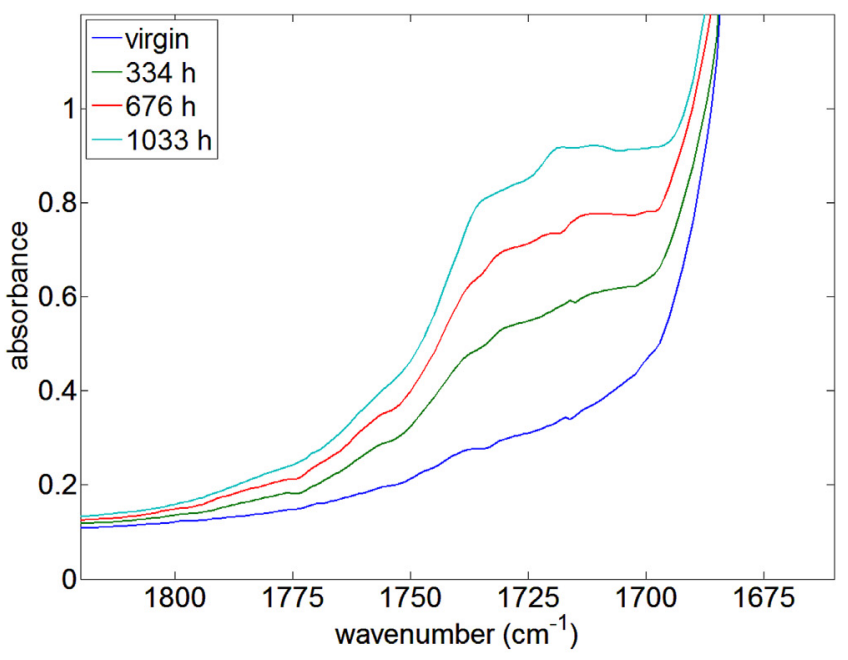

(a)

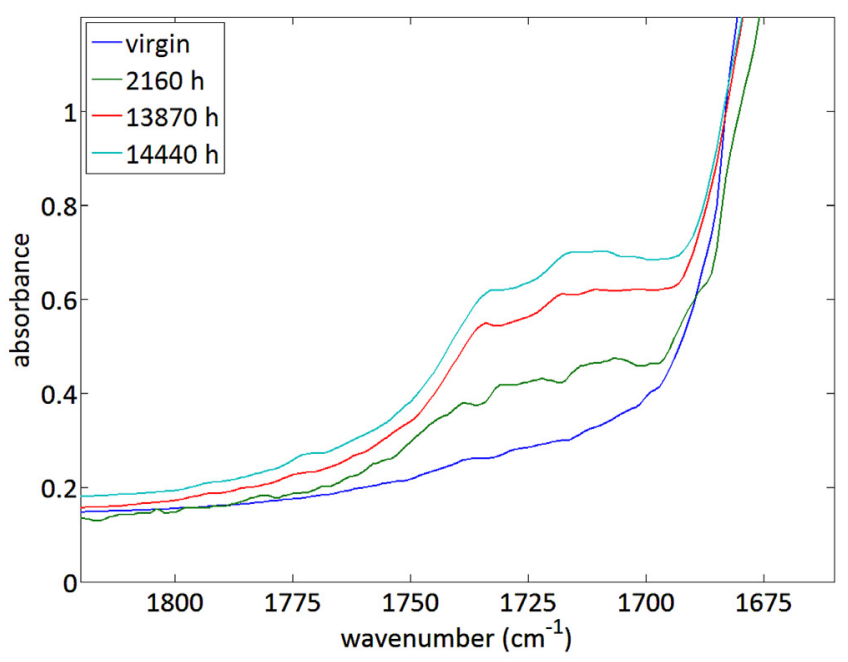

(b)

Fig. 2. Fourier-transform infrared spectra of unstabilized PA11 (a) and PA $11+0.5 \%$ Irganox 1098 (b) after several ageing durations at $110{ }^{\circ} \mathrm{C}$ under atmospheric air.

stabilizers. Consequently, carbonyl concentrations will be estimated for stabilized materials as illustrated for unstabilized ones in Ref. [21].

The kinetic curves for stabilized and unstabilized PA11 are illustrated in Fig. 3 for exposures at 90,130, and $165^{\circ} \mathrm{C}$.

The curves for unstabilized PA11 were previously described and modeled: they are of an auto-decelerated type without any induction period. The absence of an induction period was previously linked to the thermal instability of hydroperoxides in PA11 [26].

In the case of stabilized materials, kinetic curves for the carbonyl build-up progressively shift toward higher exposure times. This is particularly true when the temperature decreases, and the stabilizer concentration increases. More precisely, an initial increase is observed up to a plateau of $0.05 \mathrm{~mol} \mathrm{l}^{-1}$, followed by a pseudoinduction period during which the carbonyl concentration does not significantly change, and then an auto-acceleration. The existence of a plateau could be linked either to morphological changes [27] such as annealing or chemicrystallization (although it is difficult to explain why the plateau level decreases with stabilizer content), or to the reaction between unstable species (generated

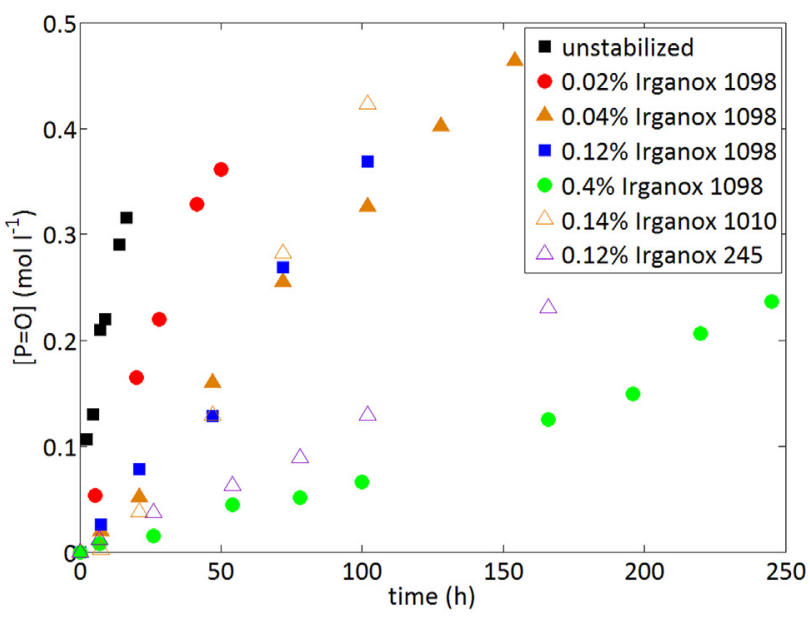

(a)

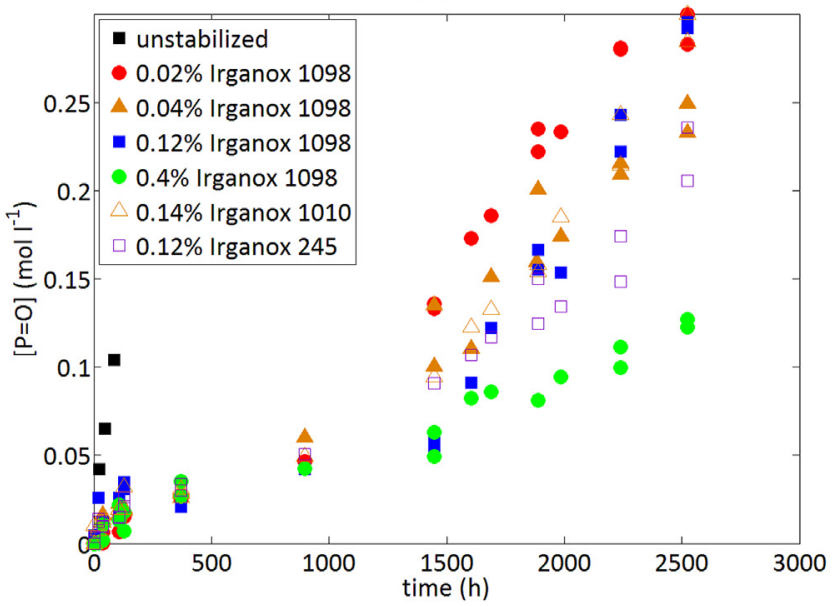

(b)

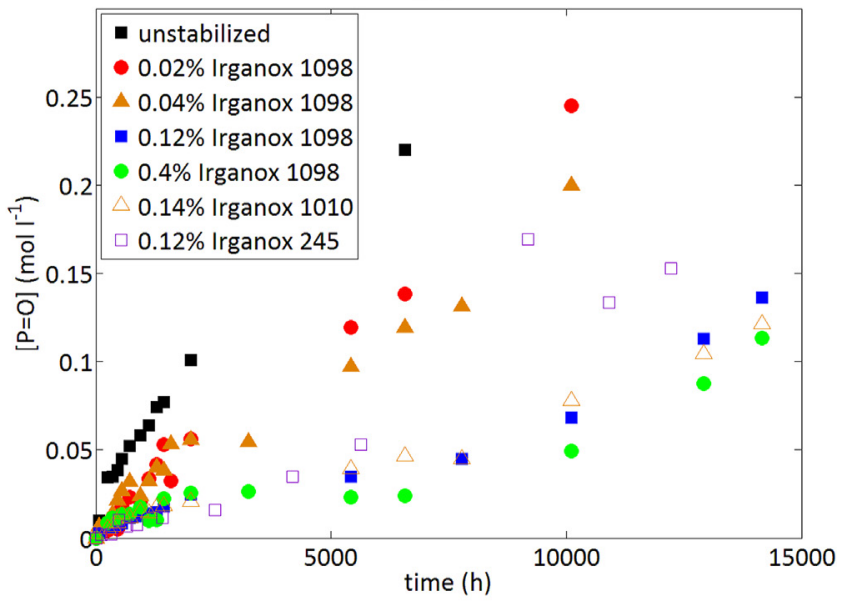

(c)

Fig. 3. Kinetic curves for the carbonyl build-up for unstabilized PA11 and PA11 stabilized with various levels of Irganox 1098, Irganox 1010, and Irganox 245 for exposures under air at $165^{\circ} \mathrm{C}(\mathrm{a}), 130{ }^{\circ} \mathrm{C}(\mathrm{b})$, and $90{ }^{\circ} \mathrm{C}(\mathrm{c})$.

during processing) and phenols. When increasing the stabilizer content, it would appear that:

- the time to reach the "plateau" remains unchanged; 
- the plateau level decreases with stabilizer content, especially for the exposure at $90^{\circ} \mathrm{C}$;

- the maximal oxidation rate remains almost the same, irrespective of the stabilizer content, which seems consistent with the case of stabilization with phenols for other hydrocarbon model compounds [28] or polymers [29], as discussed later.

In a first approach, the temperature effect can be tentatively discussed by comparing the time to reach a carbonyl concentration equal to $0.1 \mathrm{~mol} \mathrm{l}^{-1}$ in an Arrhenius diagram (Fig. 4). First, experimental curves for PA11 + 0.12\% Irganox 1098 and PA11 $+0.4 \%$ Irganox 1098 progressively "converge" when the temperature decreases (see also the results in "3. Macromolecular changes" below). In other words, the characteristic time $\left(t_{0.1}\right)$ does not follow the trend predicted from the Arrhenius law. This is especially true for stabilized samples where the apparent activation energy varies from less than $80 \mathrm{~kJ} \mathrm{~mol}^{-1}$ to more than $130 \mathrm{~kJ} \mathrm{~mol}^{-1}$. Such behavior was already observed by Gugumus in the case of polypropylene stabilized by hindered phenols [30]. It is generally explained when the degradation kinetic involves at least two mechanisms [31], which is clearly the case here.

In the case of unstabilized PA11, two mechanisms of creating radicals are possible: polymer thermolysis and hydroperoxides decomposition [32]. Degradation by thermolysis usually involves the direct breaking of the $\mathrm{C}-\mathrm{C}$ or $\mathrm{C}-\mathrm{N}$ bond and is a "high" activation energy process (typically $200 \mathrm{~kJ} \mathrm{~mol}^{-1}$ [33]). Oxidative degradation is characterized by a "low" activation energy (typically 80-100 kJ mol${ }^{-1}$ in PA [26]). It is therefore not surprising that one mechanism predominates over the other at a high temperature and vice versa, thus causing curvature in the Arrhenius diagram.

In the case of stabilized samples, the time to reach $0.1 \mathrm{~mol} \mathrm{l}^{-1}$ involves an oxidation process as well as a physical process linked to the stabilizer departure (because diffusion is not involved due to the thinness of the samples). The solubility of Irganox 1098 in PA6 is about $3.5 \%$ at $170{ }^{\circ} \mathrm{C}$ and less than $1 \%$ at $100{ }^{\circ} \mathrm{C}$ [12] while it is clearly less in PA11, because it is less polar and thus less compatible with Irganox 1098. The corresponding activation energy values for solubility $\mathrm{E}_{\mathrm{s}}$ are close to 10 and $60 \mathrm{~kJ} \mathrm{~mol}^{-1}$, which are respectively above and below the stabilizer melting point [12].

The "high" activation energy process (occurring at high temperatures) could be linked to stabilizer evaporation (an activation energy $\Delta \mathrm{H}_{\mathrm{vap}} \sim 160 \mathrm{~kJ} \mathrm{~mol}^{-1}$ was reported for Irganox 1098 in PA11 [20]). The overall activation energy for volatile loss would therefore

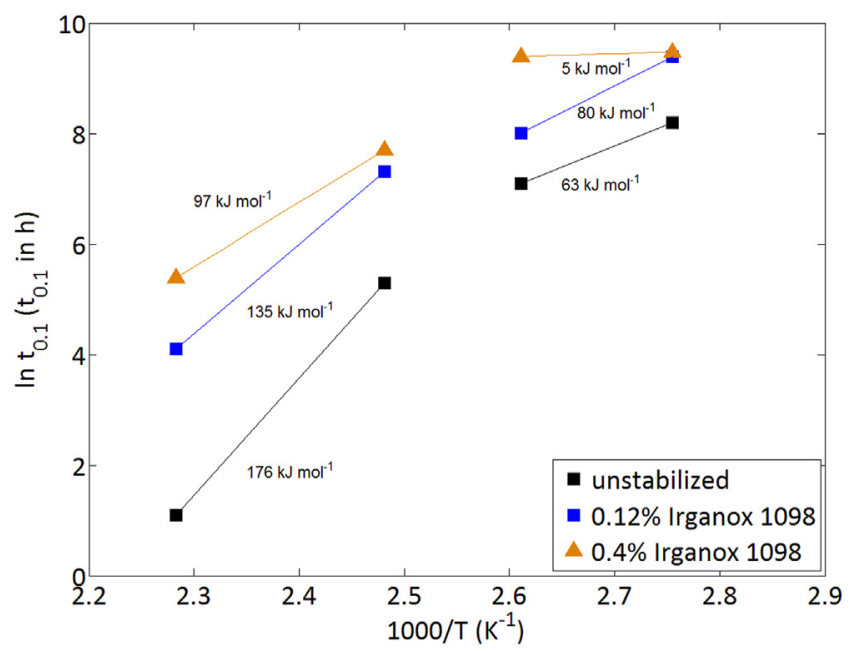

Fig. 4. Arrhenius diagram for the time to reach carbonyl concentration equal to $0.1 \mathrm{~mol} \mathrm{l}^{-1}$. be given by $E_{v}=\Delta H_{v a p}-E_{s}[34]$. By contrast, the low activation energy process (occurring at low temperatures) would be linked to stabilizer solubility, which was shown to control polymer lifetime $[13,34]$.

To conclude, according to these interpretations, lifetime depends on:

- high activation energy processes at elevated temperatures (e.g., thermolysis, stabilizer volatilization);

- low activation energy processes at lower temperatures (e.g., hydroperoxide decomposition, stabilizer solubility).

Moreover, the efficiency of the stabilizer (given, for example, by the ratio of the time to reach $0.1 \mathrm{~mol} \mathrm{l}^{-1}$ for the stabilized sample over the value for the unstabilized sample) seems to increase in quantity with temperature. This result can be justified from the competition between the stabilization by phenolic antioxidants and the oxidation propagation step:

$$
\begin{array}{ll}
\mathrm{POO}^{\circ}+\mathrm{AH} \rightarrow \mathrm{POOH}+\mathrm{A}^{\circ} & \mathrm{k}_{\mathrm{S} 1} \\
\mathrm{POO}^{\circ}+\mathrm{PH} \rightarrow \mathrm{POOH}+\mathrm{P}^{\circ} & \mathrm{k}_{3}
\end{array}
$$

The ratio of the rates of both reactions is given by the difference between their activation energies. In the case of the propagation reaction in PAs, the activation energy for propagation $\left(E_{3}\right)$ would be in the order of $60 \mathrm{~kJ} \mathrm{~mol}^{-1}$ [26]. In the case of secondary peroxy radicals reacting with hindered phenols, values of around $85 \mathrm{~kJ} \mathrm{~mol}^{-1}$ were estimated [18], which is well in line with the fact that phenol efficiency increases with temperature. In the context of a simplified reasoning, the efficiency of phenols means that: $\mathrm{k}_{3}\left[\mathrm{POO}^{\circ}\right][\mathrm{PH}]<\mathrm{k}_{\mathrm{S} 1}\left[\mathrm{POO}^{\circ}\right][\mathrm{AH}]$. Since $\mathrm{k}_{3} \sim 10 \mathrm{l} \mathrm{mol}^{-1} \mathrm{~s}^{-1}$ at $110{ }^{\circ} \mathrm{C}$, $[\mathrm{PH}] \sim 5.5 \mathrm{~mol} \mathrm{l}^{-1}$, and $[\mathrm{AH}] \sim 6.4 \times 10^{-4} \mathrm{~mol} \mathrm{l}^{-1}$, this would mean that $\mathrm{k}_{\mathrm{S} 1}>8.5 \times 10^{4} \mathrm{l} \mathrm{mol}^{-1} \mathrm{~s}^{-1}$ at $110{ }^{\circ} \mathrm{C}$. This is, however, an overestimation, since the calculation does not take into account the fast reaction between $\mathrm{POO}^{\circ}$ and phenoxy radicals $\mathrm{A}^{\circ}$.

\subsection{Stabilizer depletion}

We were thus interested in the stabilizer residual presence, which was estimated from the measurement of oxidation onset temperature (in non-isothermal conditions [20]). First, we stress that stabilizer quantification based on differential scanning calorimetry methods is questionable [18], and for this reason, we will present the OOT decrease curves without "converting" them to "residual stabilizer concentration" (the conversion is only possible if unstable species induced by ageing are at a low concentration at the beginning of OOT analysis). As shown in Fig. 5, OOT decreases at a rate that at first seems independent of the initial antioxidant concentration.

A certain difference is observed between PA11 + 0.14\% Irganox 1010 and PA11 + 0.12\% Irganox 1098. A possible explanation is the difference between the rates of evaporation loss for each stabilizer. Since the molar mass of Irganox 1010 is higher than that of Irganox 1098, the volatile loss is lower for PA11 + 0.14\% Irganox 1010 than for PA11 $+0.12 \%$ Irganox 1098 . It can be seen that PA11 $+0.4 \%$ Irganox 1098 is much more stable than PA11 + 0.12\% Irganox 1098 in OOT conditions, contrary to the results given at $90{ }^{\circ} \mathrm{C}$ in Fig. 3, for example. This difference can be explained as follows: OOT are recorded at a high temperature where stabilizer solubility is high (see above), while the measurement takes only a limited time, so the evaporation is negligible. By contrast, for ageing at 90 or $110^{\circ} \mathrm{C}$, the stabilizer solubility decreases, and the subsequent physical loss can occur over a long exposure time.

Unstabilized PA11 displays an OOT close to $217{ }^{\circ} \mathrm{C}$. Despite the difficulty in establishing an equivalence between OOT and stabilizer 


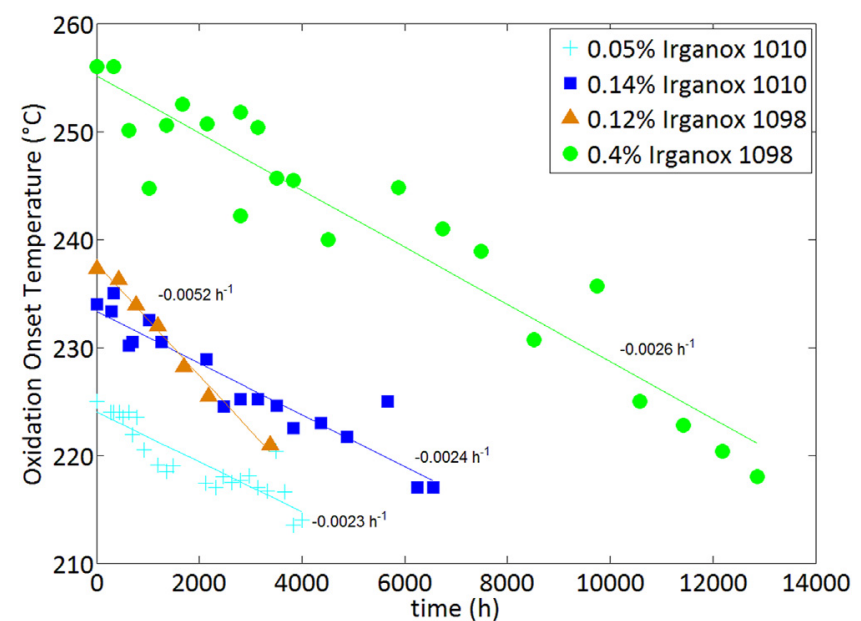

Fig. 5. Oxidation onset temperature changes for PA11 stabilized with various levels of Irganox 1098 and Irganox 1010 for exposures under air at $110{ }^{\circ} \mathrm{C}$.

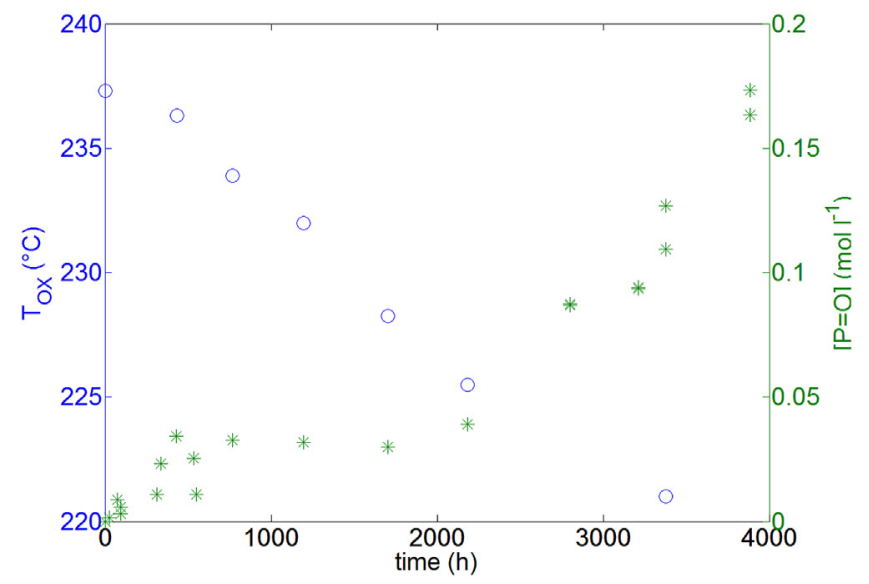

Fig. 6. Kinetic curves for carbonyl build-up and phenol depletion for PA11 $+0.12 \%$ Irganox 1098 aged at $110{ }^{\circ} \mathrm{C}$ under atmospheric air.

concentration, we tentatively defined a characteristic time $\left(t_{s}\right)$ corresponding to the complete stabilizer depletion (by either chemical consumption or evaporation). $t_{s}$ seems close to the time at which the carbonyl build-up curve displays an auto-acceleration (Fig. 6 and Table 1). It nevertheless remains difficult to conclude about the discrepancies arising from experimental uncertainties or physical reasons.

\subsection{Macromolecular changes}

The oxidation observed at the molecular level results in molar mass changes easily detected by GPC. In the case of unstabilized PA11, chain scissions were shown to predominate over crosslinking events [21]. Post-polycondensation was also shown to occur at the beginning of exposure [4]. The results observed for PA11 (stabilized or not) aged at 90 or $110{ }^{\circ} \mathrm{C}$ are presented in Fig. 7 .

Let us make the following comments on these curves. First, in the case of unstabilized samples, the molar mass decrease is almost instantaneous. In presence of stabilizers, an initial molar mass increase is observed, favored by the high stabilizer concentration and higher ageing temperature (allowing for macromolecular mobility). The major reason for this would be the occurrence of postpolycondensation (as evidenced in unstabilized PA11 [4]), which
Table 1

Critical times for the oxidation of PA11 + Irganox 1098 aged under atmospheric air at several temperatures. $t_{\mathrm{s}}$ is the critical time for stabilizer consumption, $t_{\mathrm{P}}$ the plateau time for molar mass related to post-polycondensation, $t_{\mathrm{F}}$ the embrittlement time (estimated from $\mathrm{M}_{\mathrm{N}}=\mathrm{M}_{\mathrm{C}}{ }_{\mathrm{C}}=10 \mathrm{~kg} \mathrm{~mol}^{-1}$ ), and $\mathrm{t}_{\mathrm{iCO} 1}$ and $\mathrm{t}_{\mathrm{iCO} 2}$ respectively the time to reach the "plateau" and the induction duration for carbonyl build-up (Fig. 3).

\begin{tabular}{lllllll}
\hline Temperature $\left({ }^{\circ} \mathbf{C}\right)$ & stabilizer & $\mathbf{t}_{\mathbf{S}}(\mathbf{h})$ & $\mathbf{t}_{\mathbf{P}}(\mathbf{h})$ & $\mathbf{t}_{\mathbf{F}}(\mathbf{h})$ & $\mathbf{t}_{\mathbf{C O 1}}(\mathbf{h})$ & $\mathbf{t}_{\mathbf{C O 2}}(\mathbf{h})$ \\
\hline 130 & $0.12 \% 1098$ & & 100 & $>1500$ & 130 & 1300 \\
& $0.12 \% 245$ & & 100 & $>1500$ & 100 & 700 \\
110 & $0.02 \% 1098$ & 400 & 100 & $>1000$ & 200 & 1000 \\
& $0.04 \% 1098$ & 1800 & 250 & $>2500$ & 200 & 1000 \\
& $0.12 \% 1098$ & 2500 & 500 & 4000 & 200 & 1500 \\
& $0.4 \% 1098$ & 13000 & 500 & $>1500$ & 200 & 8000 \\
& $0.14 \% 1010$ & 6000 & 500 & $>5000$ & 200 & 1000 \\
& $0.12 \% 245$ & & 500 & $>5000$ & 200 & 2000 \\
90 & $0.02 \% 1098$ & & 500 & 6500 & 1500 & 3000 \\
& $0.04 \% 1098$ & & 1500 & 13000 & 1500 & 7500 \\
& $0.12 \% 1098$ & & 3000 & $>25000$ & 1500 & 9000 \\
& $0.4 \% 1098$ & & 3000 & $>25000$ & 1500 & 2000 \\
\hline
\end{tabular}

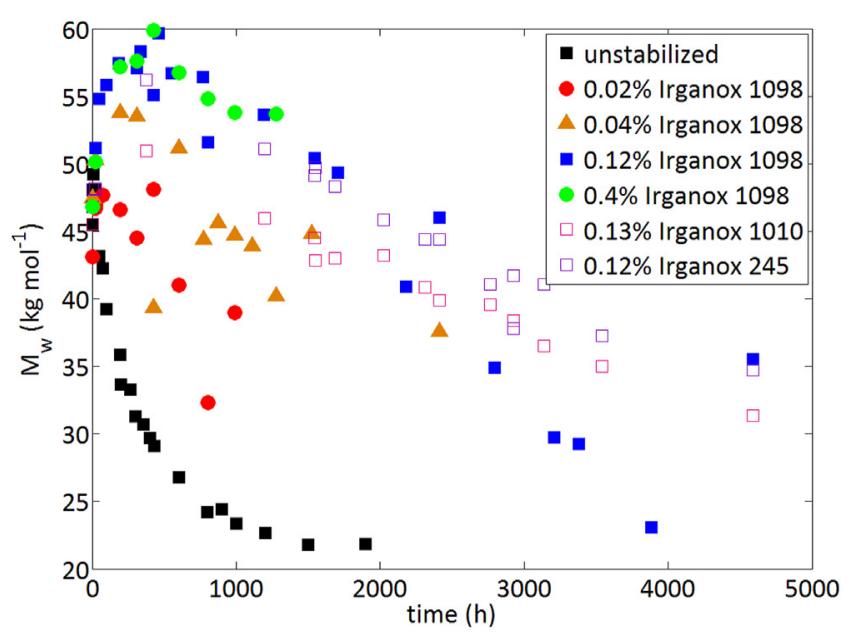

(a)

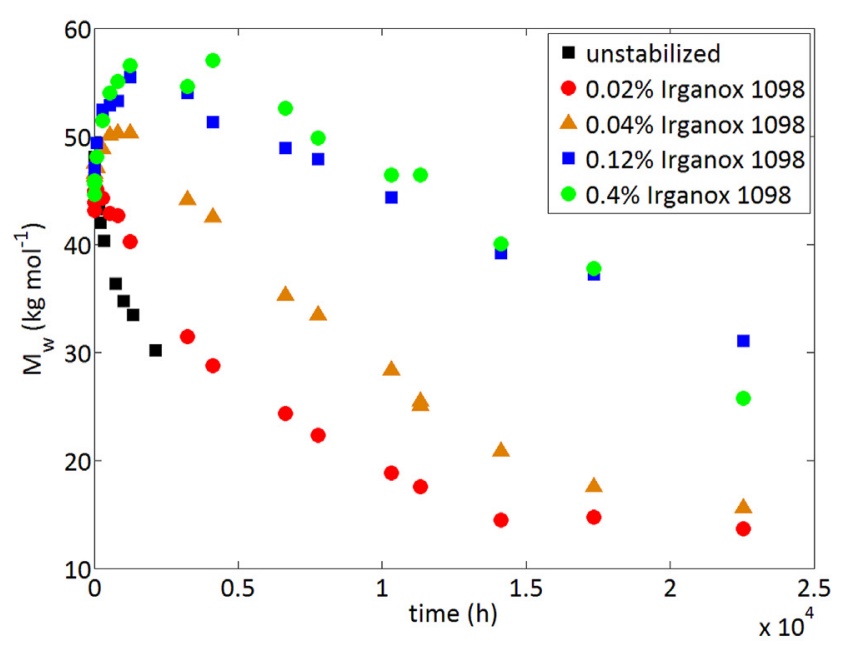

(b)

Fig. 7. Weight molar mass changes for unstabilized PA11 and PA11 stabilized with various levels of Irganox 1098 for exposures under air at $110^{\circ} \mathrm{C}$ (a) and $90{ }^{\circ} \mathrm{C}$ (b).

is an auto-decelerated reaction, since chain ends are progressively consumed, while subsequent viscosity increases limit any further 
reactions. Using the rate constants reported in Ref. [4], a kinetic discussion can be proposed:

$\mathrm{POOH} \rightarrow(2-\gamma) \mathrm{P}^{\circ}+\gamma$.imide $+(1-\gamma)$ chain scission Chain ends $\rightarrow$ condensation

For both stabilized and unstabilized PA11 at $110{ }^{\circ} \mathrm{C}$, $\mathrm{k}_{\mathrm{R}} \sim 4.10^{-6} 1 \mathrm{~mol}^{-1} \mathrm{~s}^{-1}$. Since the initial value of the number molar mass $\left(\mathrm{M}_{\mathrm{n}}\right)$ is close to $20-25 \mathrm{~kg} \mathrm{~mol}^{-1}$, the concentration in each kind of chain end is $0.05 \mathrm{~mol} \mathrm{l}^{-1}$, while the initial rate of postpolycondensation (competing with chain scissions) is in the order of:

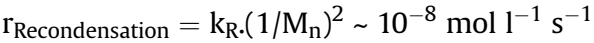

For unstabilized PA11, the yield in imide $\gamma$ is $0.8, \mathrm{k}_{1 \mathrm{u}} \sim 5.10^{-5}$ and $[\mathrm{POOH}]_{0} \sim 0.02 \mathrm{~mol} \mathrm{l}^{-1}$, so that the rate of chain scission at $110{ }^{\circ} \mathrm{C}$ is thus:

$\mathrm{r}_{\text {scission }}=(1-\gamma) \cdot \mathrm{k}_{1 \mathrm{u}} \cdot[\mathrm{POOH}]_{0} \sim 10^{-7} \mathrm{~mol} \mathrm{l}^{-1} \mathrm{~s}^{-1}$

In other words, the chain scissions predominate over postpolycondensation.

For stabilized PA11, the initial molar mass is of the same order as unstabilized PA11. $[\mathrm{POOH}]_{0}$ is possibly lower than in the unstabilized PA11, which explains why post-polycondensation predominates over chain scissions in the initial phases until the chain ends are almost consumed.

At longer times, the molar mass decreases due to chain scissions induced by oxidation. According to previous papers on embrittlement [4], the end of life (in terms of ultimate strain) is linked to a critical molar mass value (respectively, about 10 and $20 \mathrm{~kg} \mathrm{~mol}^{-1}$ for $M_{n}$ and $M_{w}$ in PA11). The corresponding times $t_{F}$ (Table 1) are clearly higher than the "induction times" observed for carbonyl build-up curves, which can be commented as follows: in PAs, hydroperoxides are unstable but "non-inductive" [21,26,35] and would thus generate imides (Scheme 1c) predominating over the chain scissions. A supplementary figure in support of this reasoning is provided in the Appendix, showing that for a given carbonyl level, the molar mass is higher in stabilized than in unstabilized PA11.

\subsection{Yellowing kinetics}

Fig. 8 compares the UV spectra for unstabilized and stabilized PA11 virgin and aged samples. In the case of virgin samples, it is reported that the increase in the absorbance at $280 \mathrm{~nm}$ is due to $\alpha$ ketoamides [36], conjugated imines [37], or crotonized aldehydes [36], and seems correlated with imides [21]. Stabilized samples display an absorbance at $280 \mathrm{~nm}$, which is ascribed to the presence

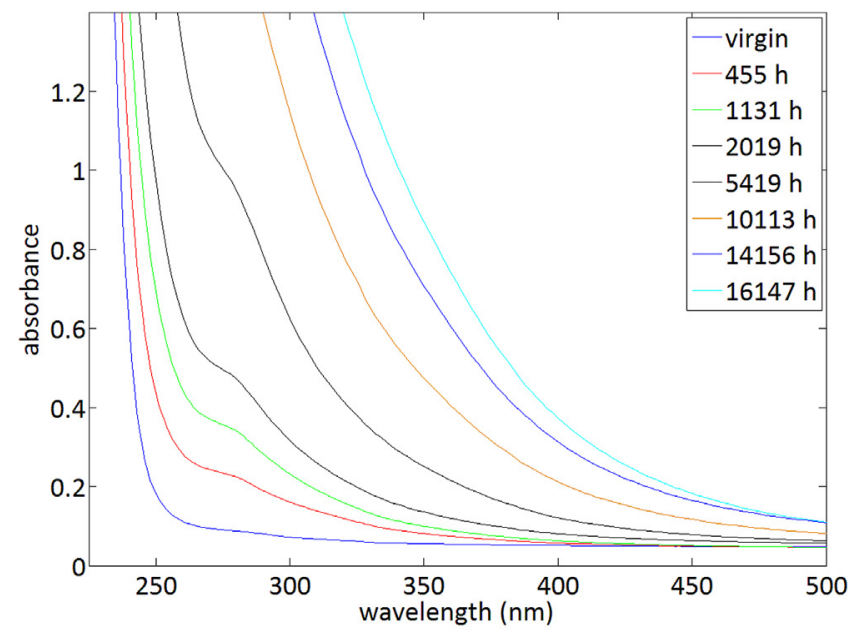

(a)

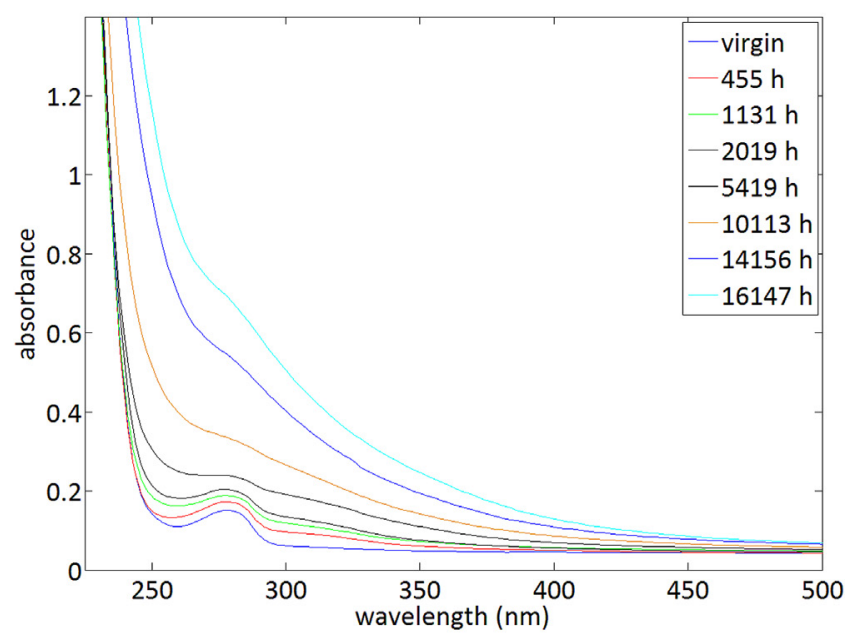

(b)

Fig. 8. UV spectra of unstabilized PA11 (a) and PA11 + 0.4\% Irganox 1098 aged under air at $90^{\circ} \mathrm{C}$.

of phenolic compounds [38]. The observed broadening of this band during ageing can be ascribed to the consumption of phenols (consistently with OOT results), their conversion into several yellowing byproducts (quinone methide, cinnamate, bis(cinnamate), unconjugated bis(quinonemethide), etc.), and the appearance of

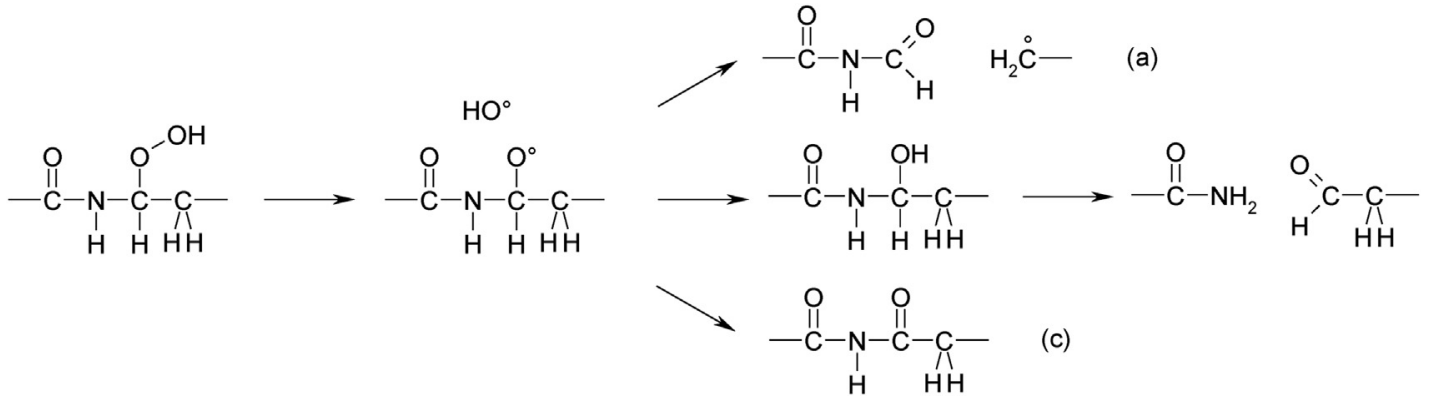

Scheme 1. Hydroperoxide decomposition leading to several kinds of carbonyl species and chain scissions. 
yellowing products associated with the degradation of PA11 chains.

From a quantitative point of view, we estimated the yellowing from the changes at $280 \mathrm{~nm}$. The yellowing changes versus exposure time are plotted in Fig. 9. At first sight, the kinetic curves for UV absorption and imide concentration are very close. We hence assumed that:

$\mathrm{DO}_{280}=\alpha .[$ Imide $]+\mathrm{DO}_{\text {stab }}$

Where $\mathrm{DO}_{\text {stab }}$ is the contribution to yellowing induced by phenolic antioxidants (or their degradation product). $\alpha$ was observed to be about 4 in unstabilized PA11 [21]. Interestingly, it can be noted that in the case of ageing at $90{ }^{\circ} \mathrm{C}$ :

- for PA11 + 0.04\% Irganox 1098 aged for $3000 \mathrm{~h}$, [Imide] 0.06 and $\mathrm{DO}_{280} \sim 0.3$ so that $\mathrm{DO}_{\text {stab }} \sim 0.06$;

- for PA11 + 0.12\% Irganox 1098 aged for $10000 \mathrm{~h}$, [imide] 0.07 and $\mathrm{DO}_{280} \sim 0.5$ so that $\mathrm{DO}_{\text {stab }} \sim 0.22$;

- if we now compare PA11 + 0.12\% Irganox 1098 and PA11 + $0.14 \%$ Irganox 1010 aged for $2000 \mathrm{~h}$, the oxidation level is lower for PA11 stabilized with Irganox 1010, but yellowing is higher.

It is thus clear that the contribution of phenols to yellowing depends on the ageing time, the nature of the substituents, and the conversion degree of the stabilizer. The relationships between oxidation and yellowing levels remain to be quantitatively proposed by making a strong analytical effort to isolate each stabilizer byproduct and determine its contribution to yellowing.

In the case of stabilized PA11, yellowing is clearly observed during the induction period (from a mechanical point of view). For example, for the sample of PA11 + 0.4\% Irganox 1098, the induction time for carbonyl is higher than $10000 \mathrm{~h}$ (Fig. 3), while the time for embrittlement is undoubtedly higher than $20000 \mathrm{~h}$ (Fig. 7). In other words, yellowing products are already detected before the time to mechanical failure (Fig. 8), thus confirming the detrimental effect of phenolic stabilizers on surface properties $[39,40]$.

\section{Conclusions}

This paper reports the effect of phenolic antioxidants (mainly Irganox 1098) on the thermal stabilization of thin PA11 films. We mainly observed that phenolic antioxidants are efficient stabilizers that delay carbonyl build-up and molar mass decrease induced by

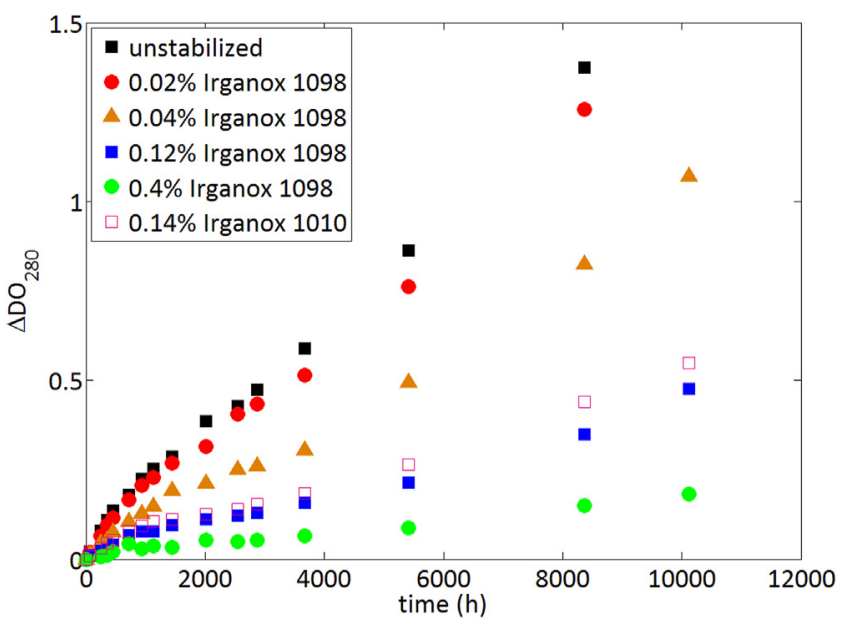

Fig. 9. Yellowing changes for unstabilized PA11 and PA11 stabilized with various levels of Irganox 1098 aged under air at $90{ }^{\circ} \mathrm{C}$. chain scissions. In the case of samples typically containing more than $0.1 \%$ Irganox 1098, the molar mass changes first increase (due to the post-polycondensation reaction) and then decrease toward the "end-of-life" value, which is reached after an exposure time greater than the induction period for carbonyl build-up. These positive effects are partly counterbalanced by the "yellowing" effect of phenols. Finally, it appears that rates of appearance of oxidation products or chain scission processes do not follow Arrhenian behavior in the temperature range investigated here $\left(90-165^{\circ} \mathrm{C}\right)$ : this non-Arrhenian behavior shows that the degradation kinetic is governed by several mechanisms in competition: for instance, stabilization by phenolic antioxidants, oxidation, and physical departure of stabilizers. As a result, it remains now to develop a complete kinetic model to predict chain scissions, carbonyl buildup, and phenol consumption to extrapolate these data to lower temperatures.

\section{CRediT authorship contribution statement}

Octavie Okamba-Diogo: Data curation, Formal analysis, Investigation. François Fernagut: Conceptualization, Funding acquisition, Methodology, Project administration, Resources, Supervision. Jean Guilment: Conceptualization, Funding acquisition, Methodology, Project administration, Resources, Supervision. Frederique Pery: Data curation, Formal analysis, Investigation, Methodology, Supervision, Writing - original draft. Bruno Fayolle: Conceptualization, Methodology, Project administration, Resources, Supervision, Writing - original draft. Emmanuel Richaud: Conceptualization, Data curation, Formal analysis, Investigation, Methodology, Writing - original draft, Writing - review \& editing.

\section{Acknowledgements}

We gratefully acknowledge Arkema and the French Association nationale de la recherche et de la technologie for providing a $\mathrm{PhD}$ scholarship to Octavie Okamba Diogo (Cifre 2011-1558). We have a special thought for Jean Guilment who left us suddenly. His expertise and kindness will be missed by all.

\section{APPENDIX}

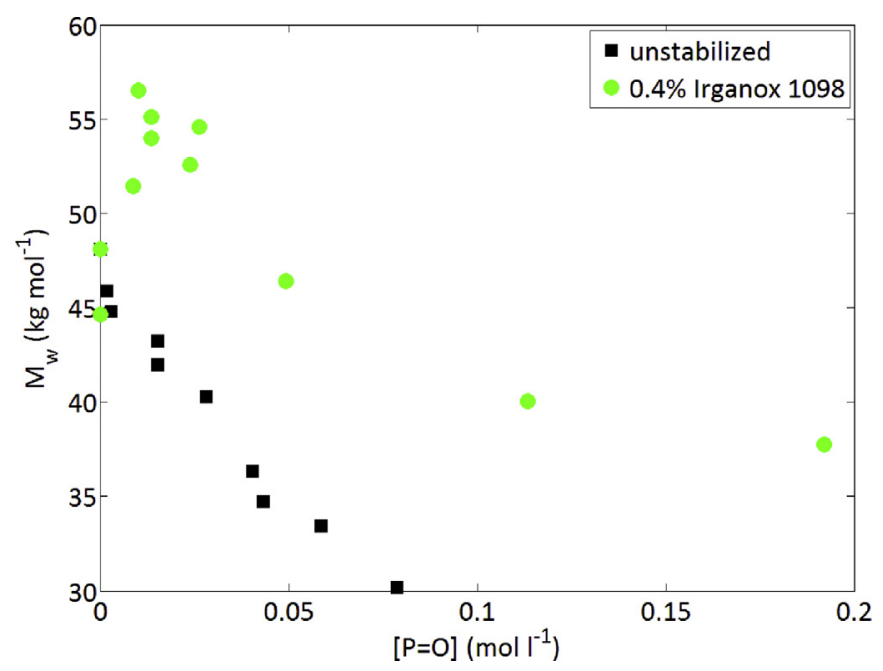

Fig. 10. Relative changes of weight molar mass versus carbonyl concentration for unstabilized PA11 and PA11 stabilized with 0.4\% Irganox 1098. 


\section{Appendix A. Supplementary data}

Supplementary data to this article can be found online at https://doi.org/10.1016/j.polymdegradstab.2020.109206.

\section{References}

[1] K. Marchildon, Polyamides - still strong after seventy years, Macromol. React. Eng. 5 (2011) 22-54.

[2] A. Rios De Anda, L.A. Fillot, F.M. Preda, S. Rossi, D.R. Long, P. Sotta, Sorption and plasticization effects of ethanol-toluene-isooctane ternary mixtures in polyamide 6,6 and induced plasticization effects, Eur. Polym. J. 55 (2014) $199-209$.

[3] K.J. Kallio, M.S. Hedenqvist, Ageing properties of polyamide-12 pipes exposed to fuels with and without ethanol, Polym. Degrad. Stabil. 93 (2008) $1846-1854$

[4] O. Okamba-Diogo, E. Richaud, J. Verdu, F. Fernagut, J. Guilment, B. Fayolle, Investigation of polyamide 11 embrittlement during oxidative degradation, Polymer 82 (2016) 49-56.

[5] O. Okamba-Diogo, E. Richaud, J. Verdu, F. Fernagut, J. Guilment, B. Fayolle, Molecular and macromolecular structure changes in polyamide 11 during thermal oxidation - kinetic modeling, Polym. Degrad. Stabil. 120 (2015) $76-87$.

[6] C. El-Mazry, M. Ben Hassine, O. Correc, X. Colin, Thermal oxidation kinetics of additive free polyamide 6-6, Polym. Degrad. Stabil. 98 (2013) 22-36.

[7] P. Cerruti, C. Carfagna, Thermal-oxidative degradation of polyamide 6,6 containing metal salts, Polym. Degrad. Stabil. 95 (2010) 2405-2412.

[8] P. Cerruti, J. Rychlý, L. Matisová-Rychlá, C. Carfagna, Chemiluminescence from oxidation of polyamide 6,6: II. The effect of metal salts, Polym. Degrad. Stabil. 84 (2004) 199-206.

[9] P. Gijsman, W. Dong, A. Quintana, M. Celina, Influence of temperature and stabilization on oxygen diffusion limited oxidation profiles of polyamide 6 Polym. Degrad. Stabil. 130 (2016) 83-96.

[10] D. Forsström, B. Terselius, Thermo oxidative stability of polyamide 6 films I. Mechanical and chemical characterization, Polym. Degrad. Stabil. 67 (2000) 69-78.

[11] D. Forsström, T. Reitberger, B. Terselius, Thermo-oxidative stability of polyamide 6 films: II. Chemiluminescence techniques, Polym. Degrad. Stabil. 67 (2000) 255-261.

[12] W. Dong, P. Gijsman, The diffusion and solubility of Irganox® 1098 in polyamide 6, Polym. Degrad. Stabil. 95 (2010) 955-959.

[13] J. Malík, D.Q. Tuan, E. Špirk, Lifetime prediction for HALS-stabilized LDPE and PP, Polym. Degrad. Stabil. 47 (1995) 1-8.

[14] R. Steffen, H. Setyamukti, G. Wallner, K. Geretschläger, B. Röder, Kinetics of degradation-induced polymer luminescence: polyamide under dry heat exposure, Polym. Degrad. Stabil. 140 (2017) 114-125.

[15] A. Boersma, Predicting the efficiency of antioxidants in polymers, Polym. Degrad. Stabil. 91 (2006) 472-478.

[16] I. Ahmad, C.Y. Li, Y.G. Hsuan, R.A. Cairncross, Reaction model describing antioxidant depletion in polyethylene-clay nanocomposites under thermal aging, Polym. Degrad. Stabil. 110 (2014) 318-335.

[17] P.Y. Le Gac, M. Celina, G. Roux, J. Verdu, P. Davies, B. Fayolle, Predictive ageing of elastomers: oxidation driven modulus changes for polychloroprene, Polym. Degrad. Stabil. 130 (2016) 348-355.

[18] E. Richaud, Kinetic modelling of phenols consumption during polyethylene thermal oxidation, Eur. Polym. J. 49 (2013) 2223-2232.

[19] A. Astruc, P. Bartolomeo, B. Fayolle, L. Audouin, J. Verdu, Accelerated oxidative ageing of polypropylene fibers in aqueous medium under high oxygen pressure as studied by thermal analysis, Polym. Test. 23 (2004) 919-923.
[20] O. Okamba Diogo, E. Richaud, J. Verdu, F. Fernagut, J. Guilment, F. Pery, B. Fayolle, Quantification of hindered phenols in polyamide 11 during thermal aging, Polym. Test. 52 (2016) 63-70.

[21] O. Okamba-Diogo, E. Richaud, J. Verdu, F. Fernagut, J. Guilment, B. Fayolle, Molecular and macromolecular structure changes in polyamide 11 during thermal oxidation, Polym. Degrad. Stabil. 108 (2014) 123-132.

[22] W. Dong, P. Gijsman, Influence of temperature on the thermo-oxidative degradation of polyamide 6 films, Polym. Degrad. Stabil. 95 (2010) 1054-1062.

[23] R.J. Bruessau, Experiences with Interlaboratory GPC Experiments, Macromolecular Symposia110, 1996, pp. 15-32.

[24] L. Achimsky, L. Audouin, J. Verdu, J. Rychly, L. Matisova-Rychla, On a transition at $80^{\circ} \mathrm{C}$ in polypropylene oxidation kinetics, Polym. Degrad. Stabil. 58 (1997) 283-289.

[25] R. Gensler, C.J.G. Plummer, H.-H. Kausch, E. Kramer, J.-R. Pauquet, H. Zweifel, Thermo-oxidative degradation of isotactic polypropylene at high temperatures: phenolic antioxidants versus HAS, Polym. Degrad. Stabil. 67 (2000) 195-208.

[26] E. Richaud, O. Okamba Diogo, B. Fayolle, J. Verdu, J. Guilment, F. Fernagut, Review: auto-oxidation of aliphatic polyamides, Polym. Degrad. Stabil. 98 (2013) 1929-1939.

[27] P. Cerruti, M. Lavorgna, C. Carfagna, L. Nicolais, Comparison of photo-oxidative degradation of polyamide 6,6 films stabilized with HALS and CuCl2+KI mixtures, Polymer 46 (2005) 4571-4583.

[28] E.B. Zeynalov, N.S. Allen, Modelling light stabilizers as thermal antioxidants, Polym. Degrad. Stabil. 91 (2006) 3390-3396.

[29] E. Richaud, B. Fayolle, J. Verdu, Polypropylene stabilization by hindered phenols - kinetic aspects, Polym. Degrad. Stabil. 96 (2011) 1-11.

[30] F. Gugumus, Effect of temperature on the lifetime of stabilized and unstabilized PP films, Polym. Degrad. Stabil. 63 (1999) 41-52.

[31] M. Celina, K.T. Gillen, R.A. Assink, Accelerated aging and lifetime prediction: review of non-Arrhenius behaviour due to two competing processes, Polym. Degrad. Stabil. 90 (2005) 395-404.

[32] A. Tcharkhtchi, L. Audouin, J.M. Tremillon, J. Verdu. Oxyluminescence of polyamide 12, Polym. Degrad. Stabil. 44 (1994) 335-341.

[33] J. Li, S.I. Stoliarov, Measurement of kinetics and thermodynamics of the thermal degradation for non-charring polymers, Combust. Flame 160 (2013) $1287-1297$.

[34] P.D. Calvert, N.C. Billingham, Loss of additives from polymers: a theoretical model, J. Appl. Polym. Sci. 24 (1979) 357-370.

[35] J. Lemaire, R. Arnaud, J-L. Gardette, Low temperature thermo-oxidation of thermoplastics in the solid state, Polym. Degrad. Stabil. 33 (1991) 277-294.

[36] R. Li, X. Hu, Study on discoloration mechanism of polyamide 6 during thermooxidative degradation, Polym. Degrad. Stabil. 62 (1998) 523-528.

[37] B. Lánská, D. Doskočilová, L. Matisová-Rychlá, R. Puffr, J. Rychlý. Thermooxidation of lactam-based polyamides with amino end-groups. Thermooxidation of hexano-6-lactam and decomposition of 6-hydroperoxyhexano-6lactam in the presence of primary amines, Polym. Degrad. Stabil. 63 (1999) 469-479.

[38] J. Scheirs, Jan Pospísiil, M.J.O'Connor, S.W. Bigger. Characterization of conversion products formed during degradation of processing antioxidants. In "Polymer Durability - Degradation, Stabilization, and Lifetime Prediction". Editor(s): Roger L. Clough, Norman C. Billingham, Kenneth T. Gillen. Advances in Chemistry Volume vol. 249 (Chapter 24), pp 359-374. Chapter DOI: 10.1021/ba-1996-0249.ch024.

[39] O.D. Bangee, V.H. Wilson, G.C. East, I. Holme, Antioxidant-induced yellowing of textiles, Polym. Degrad. Stabil. 50 (1995) 313-317.

[40] J. Pospıšil, W.-D. Habicher, J. Pilař, S. Nešpůrek, J. Kuthan, G.-O. Piringer H. Zweifel, Discoloration of polymers by phenolic antioxidants, Polym Degrad. Stabil. 77 (2002) 531-538. 